\title{
ThessAHALL-A Life-Long Learning Programme for the Social Inclusion of "Early-Stage" Older Adult Researchers
}

\author{
Despoina Mantziari, Evdokimos Konstantinidis, Despoina Petsani, \\ Nikolaos Kyriakidis, Vassiliki Zilidou, Efstathios Sidiropoulos, \\ Maria Nikolaidou, Aikaterini-Marina Katsouli, and Panagiotis Bamidis
}

Aiming at limiting the risk of ageism and social exclusion of older adults in society, the Thessaloniki Acive \& Healthy Ageing Living Lab (Thess-AHALL) looks at codesign and open science solutions for social inclusion for the ageing population. The chapter presents the "Partners of Experience", a participatory life-long learning programme, consisting of a series of co-creation research and experiential learning activities in the Thess-AHALL Living Lab, part of the Medical Physics Lab, School of Medicine of the Aristotle University of Thessaloniki (AUTH), and the City of

D. Mantziari · E. Konstantinidis · D. Petsani · N. Kyriakidis · V. Zilidou · E. Sidiropoulos · M. Nikolaidou · A.-M. Katsouli · P. Bamidis $(\varangle)$

Laboratory of Medical Physics and Digital Innovation, School of Medicine, Faculty of Health Sciences, Aristotle University of Thessaloniki, Thessaloniki, Greece

e-mail: bamidis@auth.gr

Thessaloniki Active and Healthy Ageing Living Lab (Thess-AHALL), Thessaloniki, Greece

D. Mantziari

e-mail: mantziad@auth.gr

E. Konstantinidis

e-mail: evdokimosk@auth.gr

D. Petsani

e-mail: petsanid@auth.gr

V. Zilidou

e-mail: vizilidou@auth.gr

E. Sidiropoulos

e-mail: stathsid@auth.gr

M. Nikolaidou

e-mail: mnikola@auth.gr

A.-M. Katsouli

e-mail: katsoulia@auth.gr

(C) The Author(s) 2022

A. Deserti et al. (eds.), Co-creation for Responsible Research and Innovation,

Springer Series in Design and Innovation 15,

https://doi.org/10.1007/978-3-030-78733-2_9 
Thessaloniki that encourage cooperation between older adults and the R\&D scientific community of the University.

\section{Introduction}

For over a decade, the Thessaloniki Active and Healthy Aging Living Lab (ThessAHALL) fosters research initiatives pursuing co-creation and social innovation. Its aim is to improve the physical, mental and social health as well as care processes of older adults and other vulnerable populations like chronic patients. This is done by encouraging regional development and sustainability of novel technologies in the Active and Healthy Ageing (AHA) domain. Within the SISCODE context, the Thess-AHALL has aimed to tackle the risk of social exclusion in relation to ageism and enhance the active citizenship of older adults, deploying an innovative participatory and experiential life-long learning programme for early-stage researchers over 65 years old, the so-called "Partners of Experience".

Thess-AHALL's long-standing experience in collaborating with the targeted population has shown that older adults often experience social marginalisation and the cultural stigma of losing their mental and physical abilities due to health problems or ageing [1-3]. At the same time, although science and research have a high impact on society, the scientific community is still seen as a "close elite" that does not address and reflect on citizens' real needs. Taking these two aspects into account, the ThessAHALL launched the "Partners of Experience" life-long learning programme with the aim to open the university and the environment of research for society embracing citizens. Older adults are involved specifically in the described case promoting the equal and mutual collaboration from both sides to foster social innovation and the co-design of solutions for everyday living challenges.

The concept is based on the perception that a more inclusive approach from the scientific community actively involving society could become a vehicle for vulnerable populations to tackle stigmatisation and enhance social skills and competences, while addressing effectively everyday living key societal problems in collaboration with policymakers and experts [6]. In this framework, a total number of 44 older adult early-stage researchers, members of the "Collaboration and Research Community for Independent Living”, powered by AUTH Medical Physics Lab, attended the "Partners of Experience" programme for a whole academic year exploiting applied scientific research \& co-creation methodologies. A concrete concept model of the proposed life-long learning programme has been the outcome of this experiential co-creation journey, aspiring to be replicated and further exploited in similar and diverse contexts in the future. 


\section{Ecosystem, Context and Challenge Addressed}

The absence of a horizontal national policy framework towards ageism has led to unequal access to the benefits of social inclusion activities for the target population across Greece, as the implementation of social inclusion policies for older adults is at the discretion of the municipal and regional authorities. More specifically, the local municipal authorities are responsible for providing educational programmes for older adults (e.g. teaching computers skills, foreign languages etc.), entertaining and cultural activities (e.g. dance classes, physical exercise programmes, ageing tourism etc.) as well as operating the local day care and activity centres. On the other hand, there are remarkable, although fragmentary, initiatives, undertaken by individual organisations or other types of local policymaking actors: e.g. private companies, the National Health Districts, NGOs, Patients' associations, universities etc., either as part of their action plans for the ageing population or as part of their Corporate Social Responsibility (CSR) commitments, including soft-skills training seminars for older adults or programmes for the employment of older people.

Within this framework, and thanks to its many-year experience in research in the field of Active and Healthy Aging (AHA), the Thess-AHALL has established its own action plan, often exploiting social innovation and open science initiatives or awareness raising activities. One example for this are the Play4/Participate 4 common cause campaigns that entail lectures open to the public, participatory \& experiential research activities, etc., in a way to promote the openness of the scientific community to the society [6]. Furthermore, it aims at the engagement and close collaboration of researchers, policymakers, experts and citizens (the Quadruple Helix) as a means for effectively addressing key societal challenges in the fields of Health and Well-Being.

The actual strength of Thess-AHALL lies in its wide network of collaborators within the Quadruple Helix at the local, national and EU levels -i.e. academic partners, municipalities, healthcare authorities, hospitals, care centres, NGOs, SMEs, healthcare professionals and experts, as well as its own Community of older adult researchers [7]. It constantly promotes the active engagement of all the interested parties in every step of the development of a new solution or initiative (Agile Development Methodology) [4, 5]. Thess-AHALL's national and international synergies, its involvement in a wide number of research projects in the AHA domain as well as the deep knowledge and the high expertise of its researchers, working with older adults for over a decade have resulted in extensive capacities in the fields of Responsible Research and Social Innovation. This knowledge enables the transfer of know-how and the generation of social change in the local ecosystem.

Considering this starting point, the Thess-AHALL launched the "Partners of Experience" life-long learning programme with one main objective: to fight the downsides of ageism and enhance the active citizenship of older adult and outpatient population by bridging the gap among citizens, researchers and policymakers by uniting them with the common goal of collaboratively addressing everyday living problems of society. To achieve this, the Thess-AHALL applies its existing knowledge on cocreation and citizen science principles to open the university to society and obtain 
a change in the established perception that academia still remains a separated elite section of society detached from its real needs. In this context, the Thess-AHALL welcomes older population back to the community and re-introduces them as an alternative, experiential research group that applies step-by-step scientific \& cocreation research methodologies to design and implement solutions for and with society [6].

\section{The Co-creation Journey}

To enhance its pre-existing empirical knowledge of working with the targeted population and identify solid ground for exploring its challenge, the Thess-AHALL followed a four-step co-creation journey with older adults as its primary beneficiaries and involving all the interested stakeholders as policymakers, researchers and experts. This journey, proposed as a general framework within the SISCODE project was tested and validated by the 10 co-creation labs described in this volume following the steps of (i) the context analysis of the challenge to be addressed, (ii) the reframing of the problem, (iii) the envisioning of alternative solutions and (iv) the prototyping of the most prevalent solution.

In the framework of the context analysis, the Thess-AHALL conducted an in-depth desk research, as well as a number of interviews and focus groups with interested stakeholders to collect both quantitative and qualitative data on the impact of ageism on older adults social health and life, as well as the "openness" of academia. The desk research provided valuable information on the raised research questions confirming the experiential knowledge and initial assumptions of the Thess-AHALL. Interviews with healthcare professionals sealed the findings of the desk research in relation to the crucial role of inclusive activities for the targeted population social health and their active involvement in society. Finally, a series of interviews and focus groups with older adults (the Collaboration and Research Community for Independent Living and the Parkinson's Association of Northern Greece) showed that previous experiences of participatory activities in the Living Lab had improved participants' sense of social acceptance and active citizenship, as well as their sense of belonging to a group. Members perceived themselves as equal contributors who can share their thoughts and needs and actively be part of the design of new solutions [7, 8].

The collected feedback from the interviews and focus groups strengthened the Living Lab's vision to apply participatory activities to address its challenge, while it also contributed to the reframing of the initially defined problem. Specifically, Thess-AHALL's first proposition was to fight the downsides of ageism by introducing the "Participate 4" common cause campaigns: Older adults and chronic patients should be motivated to gamify their participation in social awareness actions and co-creation activities with and for other' vulnerable populations and donate their time to be turned into a symbolic offer (tangible or intangible) accredited to a joint, predetermined cause. Despite receiving positive remarks for the innovative approach to raise awareness, both experts and the targeted stakeholders raised their concerns 
on the campaigns' sustainability, mainly related the limited participation in such actions, highlighting the need for a concrete solution, primarily orientated at the direct benefits for the targeted population (i.e. older adults' needs and expectations) [6].

This affirmation led to the development iteration of the very first solution. Once again, it was the input from interviews with older adults, expressing their satisfaction for participating in Living Lab's activities, that helped researchers to envision the new solution of setting up a "learning-by-doing" process, emphasising on the potential value of their active involvement in participatory research and the implementation of solutions for "them" and for "their society". As an interactive and highly-engaging solution was sought, based on the principles of co-creation and RRI, a new research question was raised: "What if instead of an older-adult-student group, there was an older-adult-early-stage-research group?" Beneficiaries would have the opportunity to learn and enhance their active participation in the society by experientially applying the scientific research methodology or in other words "being in the shoes of a Thess-AHALL researchers", working for a whole academic year as mutual collaborators of the Living Lab, not just attendees, to solve everyday life's problems of their interest. And that was when the "Partners of Experience" initiative was officially born!

\section{Experimentation: Output, Transformations, Outcomes}

The "Partners of Experience" solution was introduced as a life-long, experiential research programme to address everyday living challenges of older adult earlystage researchers and their peers. For a whole academic year, the 44 older adults involved the programme tested and validated the proposed life-long learning activities, divided in three smaller, thematic research groups (Environment-Health \& Social Welfare-Active Citizenship) guided by the Thess-AHALL researchers. Over the duration of nine months, the prototyping (Sept 2019-Jun 2020) took place with the three groups that closely collaborated with local policymakers, healthcare professionals and the scientific community, applying step-by-step the scientific research methodology, adjusted to a more experiential learning way. This was aimed to explore and implement solutions for making Thessaloniki a healthier and more accessible city for older adults. The "Partners of Experience" life-long learning programme included a series of 12 activities: Eight of them were conducted as face-to-face sessions between September 2019 and February 2020, while the rest of them went virtually, via Skype/Viber and phone group calls, due to the COVID-19 restrictions. The in-person activities comprised the 1st loop of the prototyping phase including activities primarily related to the first four steps of the proposed methodology arriving at initial considerations for the implementation of solutions. The virtual sessions composed the 2nd loop and consequently the final stage of solutions' implementation, dissemination and final evaluation of the programme (Fig. 1). 
Research Problem Definition:

the targeted research group reflects insights and concerns on a general societal problem, e.g. "How we could make our City Healthier and more accessible to older adults?". (Context Analysis)

\section{Specific Research Assumptions:}

the alternative researchers focus on specific aspects of the Research Problem, setting research questions which should be further explored, e.g. "What will be the impact of improving the environment, the health \& social welfare services in our City, as well as our participation in our society?" (Desk research, Experts Mentoring)

\section{Solution Ideation $\&$ Work Assignment:}

To check the validation of the set assumptions, the experiential research group(s) formulate specific ideas on potential solutions, applying design-thinking, field visits, intergeneration activities with University students/researchers or collaborating with professionals, assigning them research work, e.g. "Study on the transformation of abandomed areas, into "green" spaces in the City" or "Raise Awareness of Heart Diseases, using older adults" language" etc.

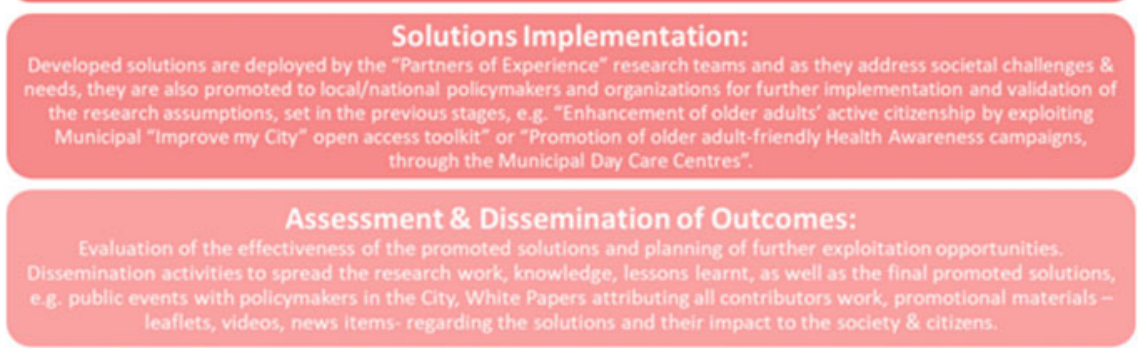

Fig. 1 The "Partners of Experience" methodology steps, followed by the participants of the programme

During the prototyping, older adult researchers tested and evaluated the proposed programme, which is summarised in the following experiential and co-creation activities:

- Public deliberation and panel sessions to create an agenda and define the programme's priorities in a co-setting (until Sept 2019)

- Design-thinking and ideation sessions for the approval of the proposed activities and the selection of Thematic Research Areas (Sept-Nov 2019)

- Desk research in the AUTH University Library and online sources during handson workshops (Dec 2019)

- Field visits in the university premises and the city for the confirmation of the research hypothesis and to brainstorm on solutions (Oct 2019-Mar 2020)

- Intergenerational lectures and collaboration with post-graduate students in assignments of their semester work (Nov 2019-Dec 2020)

- Mentoring sessions with experts and policymakers to select the final solution from the proposed ideas for implementation (Nov 2019-Dec 2020)

- Online group sessions - due to the COVID-19 restrictions (Mar 2020-Jun 2020)

- "Home" assignments for the design and implementation of the solutions as well as their final evaluation and assessment of the programme (June 2020). 

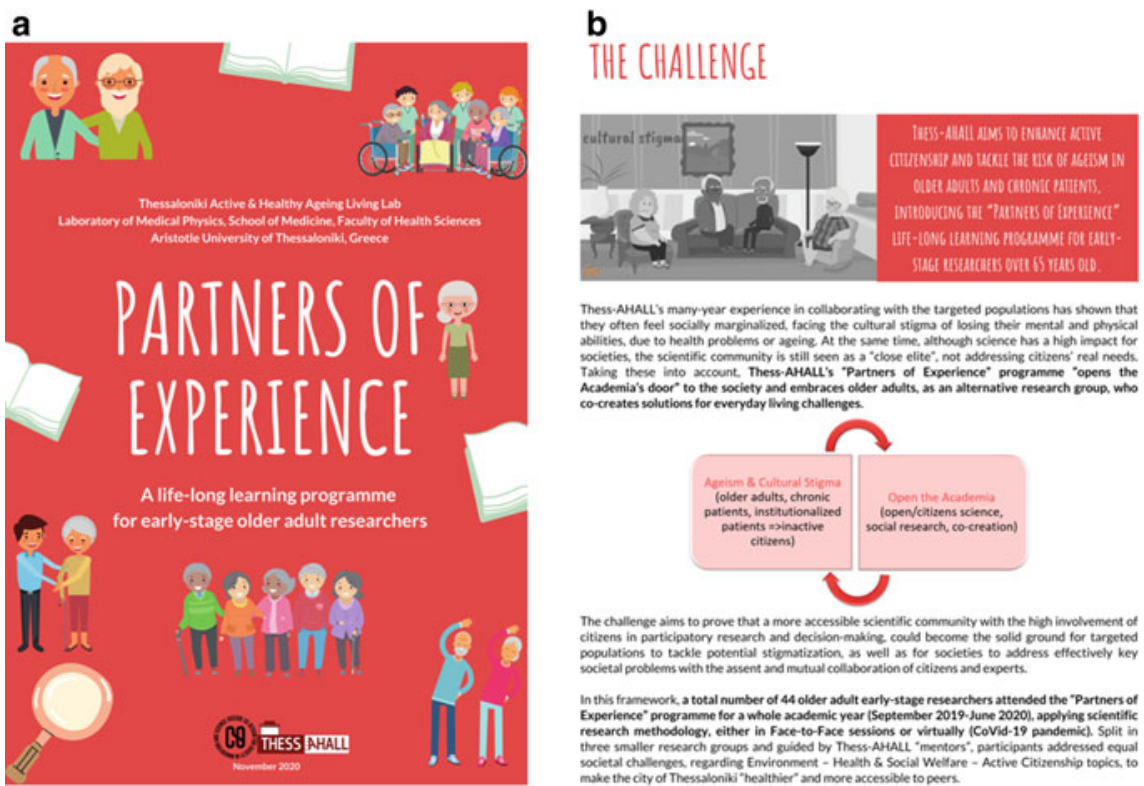

Thess-Araul's many-year experience in collaborating with the targeted populations has shown that Wherities, due to health problems or ageing At the same time, although science has a high impaxt for yocieties, the scientific community is still seen as a "close elite", not addressing citizens" real needs. Taking these into account. Thess.AHAul's "Partners of Experience" programme "opens the Academia's door" to the society and embraces oider adults, as an alternative research group. wito

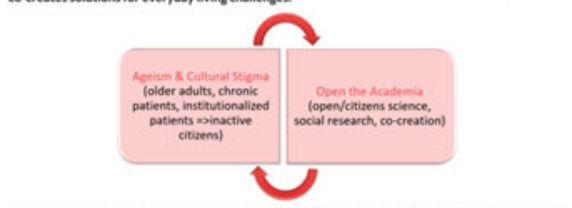

The challenge sims to prove that a more accessible scientific community with the high imolvement of citizens in participatory research and decinion-makine could become the solid ground for targeted populations to tackle potential stionatization as well as for societies to addring

In this framework, a total number of 44 older adult early-stage researchers attended the "Partners of Experience" programme for a whole academic year (September 2019.June 20201., applying xientific research methodology, either in Face-to-Face sessions of virtually (COVid-19 pandemic). Split in chree smuller research groups and guided by Thess. AHAil "mentors". participants addressed equal

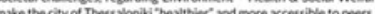

Fig. 2 a, b Preview of the "Partners of Experience" methodology handbook

The whole methodology, its activities and lessons learned from this first cycle of the programme have been included in a practical guide, a step-by-step handbook, accessible to anyone interested to explore the methodology (Fig. 2 a, b).

From its very first activities, the "Partners of Experience" programme received positive comments from all the involved stakeholders, especially stressing the programme's positive impact on the social inclusion and acceptance, as well as the high engagement of its beneficiaries who asked for its replication to address more societal problems in the future. At the same time, the local ecosystem has also been remarkably affected by the pilot Thess-AHALL has conducted within the SISCODE project. Local policymakers, i.e. the Municipality of Thessaloniki and the Region of Central Macedonia, as supporters of the "Partners of Experience" programme, are willing to embrace the programme or part of its activities in their future action plans for older adults as soon as the pandemic comes to its end. Moreover, the close collaboration between older adults, researchers and policymakers, aiming to bridge the gap between the city and its citizens as well as among the citizens, highlighted the importance of collaboration of all the interested parts within a society for solving key societal issues. In addition to this, the members of the research community who were involved in the process, and especially the postgraduate students participating in the intergenerational activities, recognised that the experiential knowledge of citizens is a valuable resource for science to avoid developing solutions that do not fit to the community's needs and they have become more open to embrace or lead similar initiatives in the future. 
In the meantime, the "Partners of Experience" programme equipped the ThessAHALL with new knowledge and skills for the systematisation of the co-creation activities in the Living Lab. The exploitation of the SISCODE toolbox in every phase of the co-creation journey and the deployment of prototype phase of the "Partners of Experience" programme, have been emblematic case studies of the transformation achieved within the organisation. Moreover, the project's challenge highlighted the importance of maintaining stakeholders' engagement in a more concrete way and establishing a framework on the sustainability of such a community. It was the SISCODE project which led Thess-AHALL to the development and implementation of their own panel management tool to keep track of the logistics, participation and ethics of its stakeholders.

\section{Lessons Learnt and Reflections}

In conclusion, the Thess-AHALL has chosen to fight the key societal challenge related to social, mental health and well-being of older adults and chronic outpatients being at risk of ageism and cultural stigma within the SISCODE context,. The barriers identified during the 1st loop of prototyping were carefully considered during the pivoting phase and resulted in an updated plan. The co-creation process and the continuous communication with the community of stakeholders enabled the programme to advance and transform into the final prototype presented above. ThessAHALL has already investigated future directions for exploiting the programme in other institutions and specific conversations are ongoing with the Municipality of Thessaloniki and the "Archangelos Michail" nursing home in Nicosia, Cyprus for a future implementation of the programme. However, the COVID-19 pandemic has delayed the procedures and plans significantly.

Moreover, regarding the involvement of policymakers, the Living Lab has adopted new approaches in addressing and engaging policymakers from different levels in various stages of the co-creation process. As it has already been mentioned, the SISCODE project and the "Partners of Experience" programme provided the opportunity to the Thess-AHALL to establish and adopt a specific strategy for stakeholder engagement and systematise plenty of its activities related to co-creation and citizens' science. Moreover, the COVID-19 situation lead to the materialisation of the need for alternative means of communication, engagement and collaboration with stakeholders, especially older adults, who are low digitally skilled and cannot use virtual means.

Furthermore, the Thess-AHALL pilot highlighted the importance of co-creation and user involvement in the field of research for older adult's health and wellbeing. Older people usually are left out of the research developments, increasing the risks of manifestation of the downsides of ageism like social exclusion. At Thess-AHALL, the core team believes that their participation in the research can assist in the development of more concrete and user-friendly solutions and additionally be beneficial for their own social life and wellbeing. 


\section{References}

1. Cantarella A, Borella E, Carretti B, Kliegel M, de Beni R (2017) Benefits in tasks related to everyday life competences after a working memory training in older adults. Int $\mathrm{J}$ Geriatr Psychiatry 32(1):86-93

2. Maffoni M, Giardini A, Pierobon A, Ferrazzoli D, Frazzitta G (2017) Stigma experienced by Parkinson's disease patients: a descriptive review of qualitative studies. Parkinson's Dis 2017

3. Kaushansky L, Boudreau D, Keirns C (2016) Is there a doctor in the house? Students explore home, history, and the evolution of medicine. J Mus Educ 41(1):52-58

4. Petsani D, Evdokimos K, Billis A, Tessarolo F, Anzivino S, Nollo G, Conotter V, Onorati G (2018) SISCODE deliverable D7.3 - pilot trials in living labs methodology

5. Tessarolo F, Nollo G, Conotter V, Onorati G, Konstantinidis EI, Petsani D, Bamidis PD (2019) User-centered co-design and AGILE methodology for developing ambient assisting technologies: study plan and methodological framework of the CAPTAIN project. In: 2019 IEEE 23rd International symposium on consumer technologies, ISCT 2019

6. Mantziari DA, Petsani DG, Konstantinidis EI (2019) Ageism and open Academia: exploring new pathways towards the limitation of social exclusion of older adults and chronic patients. In: Oral presentation at the European triple helix congress on responsible innovation \& entrepreneurship (ETHAC2019), Thessaloniki, Greece, 30 September-1 October 2019

7. Konstantinidis EI, Billis A, Bratsas C et al (2016) Thessaloniki active and healthy ageing living lab: the roadmap from a specific project to a living lab towards openness. In: PETRA '16: proceedings of the 9th ACM international conference on PErvasive technologies related to assistive environments, Corfu Island, Greece, June 2016, Article No.: 73, pp.1-4. New York, NY, United States: Association for Computing Machinery

8. Konstantinidis EI, Petsani D, Bamidis PD (2021) Teaching university students co-creation and living lab methodologies through experiential learning activities and preparing them for RRI. Health Informatics J https://doi.org/10.1177/1460458221991204

Open Access This chapter is licensed under the terms of the Creative Commons Attribution 4.0 International License (http://creativecommons.org/licenses/by/4.0/), which permits use, sharing, adaptation, distribution and reproduction in any medium or format, as long as you give appropriate credit to the original author(s) and the source, provide a link to the Creative Commons license and indicate if changes were made.

The images or other third party material in this chapter are included in the chapter's Creative Commons license, unless indicated otherwise in a credit line to the material. If material is not included in the chapter's Creative Commons license and your intended use is not permitted by statutory regulation or exceeds the permitted use, you will need to obtain permission directly from the copyright holder.

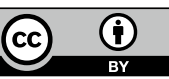

